\title{
Factors Associated with Children Ever Born: A Case Study of Somadi Village Development Committee of Palpa District, Nepal
}

\author{
Hari Prasad Upadhyay*, Keshav Raj Bhandari \\ College of Medical Science, Kathmandu University, Chitwan, Nepal
}

\begin{abstract}
Fertility is one of the three principal components of population dynamics that determine the size, structure, and composition of the population in any country. Children ever born refer to the number of children born alive to the person up to a specified reference date. It includes children who have died since birth. This study aims to identify the socioeconomic and demographic factors influencing Children Ever Born (CEB) to the women of Somadi village development committee (VDC) of Palpa district of Nepal. This study is entirely based on primary data collected using convenience sampling through questionnaire methods. A representative sample of size 298 married women was taken for the study using proportionate sampling from the different ethnic groups. The result of the study shows that the factors age at marriage, occupation of husband and knowledge of contraceptive/family planning have statistically significant role for varying CEB among the women under study. The result of the study compels to recommend that various awareness programs should be conducted about the use of contraceptive/family planning and to stop practice of early marriage among the women to reduce the higher fertility. The factors 'knowledge of contraceptive/family planning', 'occupation of husband' and 'age at marriage' are seen to have very significant impact for explaining the children ever born (CEB) to the women of Somadi VDC of Palpa district of Nepal.
\end{abstract}

Keywords: Children Ever Born (CEB), Contraceptive, Age at marriage, Married women

\section{Introduction}

Fertility is one of the three principal components of population dynamics that determine the size, structure, and composition of the population in any country. Children ever born refer to the number of children born alive to the person up to a specified reference date. It includes children who have died since birth. It does not include stillbirths, abortions or children adopted by the person. "Children ever born" may also be referred to as lifetime fertility [1]. Despite the several efforts made in the development plans to reduce the population growth rate, the population of Nepal has rapidly been increasing last few decades. It is experienced that one of the highest population growth rate among its contemporary world. According to 2011 census, the population of Nepal has reached to 2,64,94,504 with the annual growth rate 1.35 per cent [2]. The continuing growth of population has increased pressure on limited resources and land of the nation continuously, which leads to a major problem in development of the nation.

* Corresponding author email: hpchalise@ gmail.com

DOI: https://doi.org/10.21467/aiss.1.1.15-29 
The setting of country land is extraordinary. Nearly two third of the area is occupied by rolling hills and icy mountains which is not suitable for human settlement and cultivation. The population density of Nepal in terms of total land area is thus misleading. In terms of arable land per person, it crosses 181 persons per square kilometre [2]. The rapid population growth has an adverse effect on overall socioeconomic development as well as malnutrition in children [3]. The high and constant level population growth rate is considered as the main obstacle to sustainable development of the country. If the present growth rate of population remains the same, Nepal need not wait for long time for its double population and the limited resources and land of the nation may not reflect the increasing demand of people. Hence, if development is main issue, the population growth rate should be brought down as low as possible to accelerate the overall development of the nation.

Traditionally, Nepalese society favours high fertility. Children are symbol of well-being both socially and economically. Although, fertility has been decreasing in Nepal since 1981, it is still higher as compared to many other developed countries. The total fertility rate (TFR) has been decreasing day by day world widely. In case of Nepal also, the fertility has declined significantly from 6.3 births per women in 1981 to 2.3 births per women in 2011 [4]. When children ever born (CEB) influences population growth, which has consequences towards force on resources, service situations, health facilities and saving investment, in turn, such penalty have great bearing on the socio-economic and demographic characteristics that affect fertility behaviour. However, the factors that are perceived to influence fertility are highly interrelated among themselves; the conceptualization of the determinants of fertility involves a multitude of factors that vary greatly in intensity and direction of force they exert on fertility [5]. Marriage is most universal in Nepalese society. The life time fertility span of women is directly affected by age at marriage beside other factors. Fertility and marital age of women has close relationship to each other due to biological, socioeconomic and cultural factors [6] Nepalese culture and prevailing religious dogmas permit couples to live together only after the marriage, hence the reproductive performance is possible after legal marital union in Nepal. There is a strong cultural faith that only after marriage man or women becomes a full fledge member of the society [7]. Marriage and fertility in a society have been differentiated by their social, cultural, economic, demographic and educational factors. Fertility is also related to physiological capacity to reproduce individual preferences, marriage law and customs, the cost of fertility regulation and social control. Early marriage especially of the females with high marriage prevalence pattern has been sustained by agrarian economy and low educational attainment $[8,9]$.

\subsection{Rationale of the Study}

The study of fertility in different societies is very important to examine the possible determinants of fertility with their strength and direction. The area selected for present study is Somadi village development committee. Neither the studies on urban areas nor even the studies in rural areas can cover the real phenomena of these people in this area. It aims to analyse the magnitude and direction of some selected socioeconomic determinants of fertility in selected areas. Still there is no such significant study conducted in this area. Therefore, it would have significant importance to examine and highlight the magnitude and direction of selected socioeconomic determinants of fertility in the area which would be more applicable for further studies and framing further plans and policies.

\subsection{Objectives of the Study}

The general objective of the study is to assess the level of CEB of women in Somadi V.D.C. The specific objectives of the study are:

I. To explore the condition of CEB to women in Somadi V.D.C. among different groups of women.

II. To examine the socio-economic and demographic determinants influencing the total CEB to the women of Somadi V.D.C. 
Upadhyay et al. Adv. J Social Sci.; Vol. 1 Issue 1, pp: 15-29, November 2017

\subsection{Schematic Diagram of Conceptual Framework}

On the basis of literature reviews, schematic diagram of conceptual framework is presented in following Figure 1.

$\underline{\text { Independent variables }}$

$\underline{\text { Dependent variable }}$

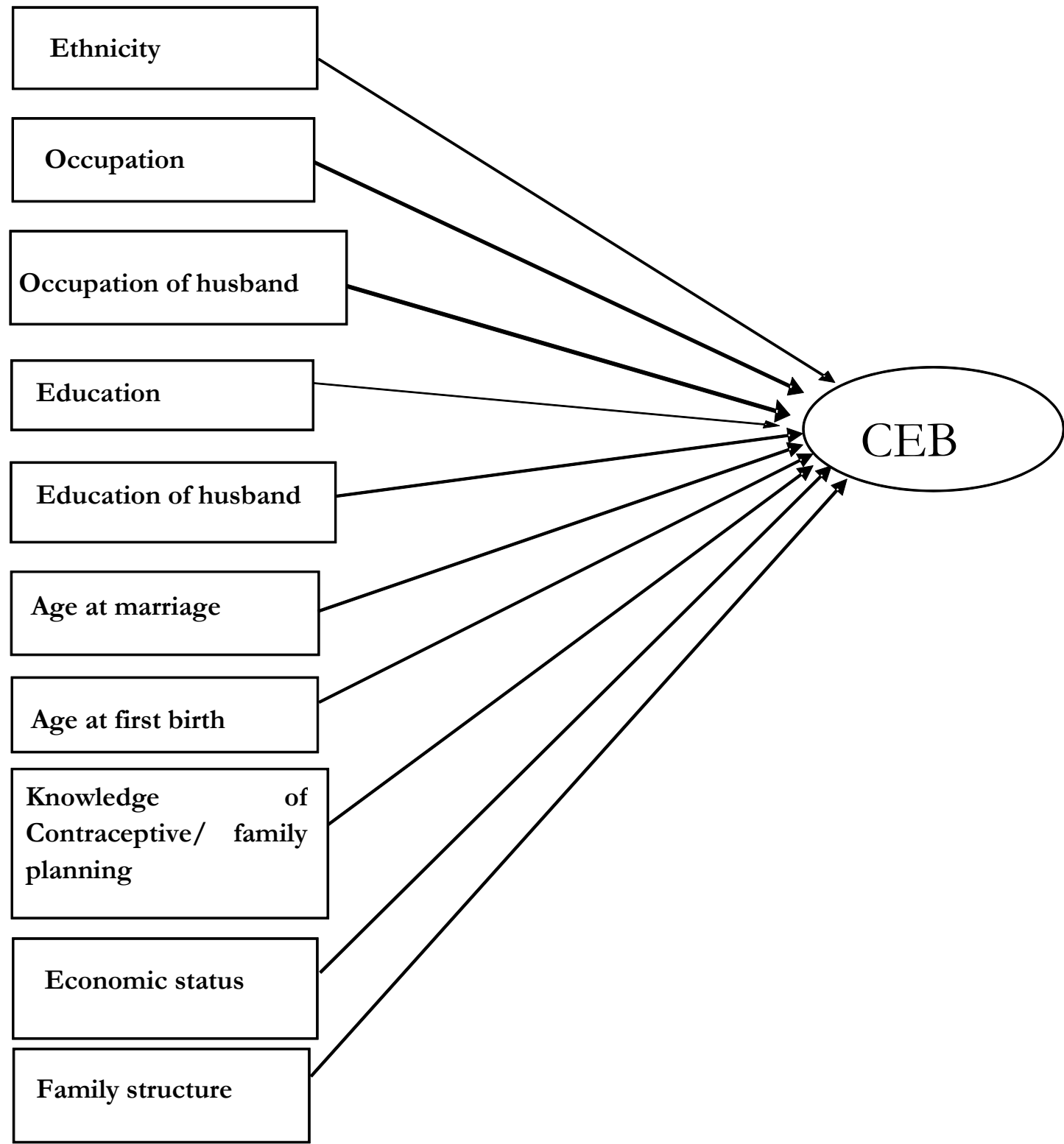

Figure 1: Schematic diagram of conceptual framework.

\section{Description of the Study Area}

The area selected for the study is Somadi V.D.C. of Palpa district located in Lumbini zone of Nepal. Geographically, the co-ordinates of the study area are $27.91^{\circ} \mathrm{N}, 83.39^{\circ} \mathrm{E}$ [2]. According to the census report 2011, this VDC contains 635 household with average household size 4.29. The total population of the study area is 2,724. Among them, 1,191 are male and 1,533 are female. Further, there are 1,144 individuals from Brahmin community having 506 males and 638 females whereas there are 153 males and 221 females from Chhetri community. Similarly, among the 852 individuals from Magar community, 381 are males and 471 
Factors Associated with Children Ever Born: A Case Study of Somadi Village Development Committee of Palpa District, Nepal

are females whereas 297 individuals are from Dalit community having 125 males and 172 females. It also contains the people from other ethnic groups like Newar, Gharti, Bhujel, etc. contributing the total population in very less extent. The overall literacy rate of the area is about $77 \%$ and that for male is about $85 \%$ and for female is about $72 \%$.

\subsection{Data Collection}

The present study is based on the data of 298 married women selected from households of different groups of women in the study area.

\subsubsection{Sampling Method}

The population frame of married women of the study area is not available. So, the result of NDHS (2011) has been taken as reference for estimating the proportion of total married women in the VDC. The NDHS (2011) report [10] suggests that $78.6 \%$ of the Nepalese adult women are ever married [9]. This proportion is used for the study. For the study, $35 \%$ of the ever-married women of study area were taken as sample on the basis of personal convenience of researcher. To make the study more representatives, the proportionate sampling technique is performed with the inclusion of various major ethnic groups taking a great care to avoid any form of bias. The sampling is done on the basis of distribution of the number of women according to various ethnic groups. This method of sampling thus gives representation of all the ethnic groups in the community which mainly comprise Brahmin/Chhetri, Janajati (Magar) and Dalit. On the basis of these information, following sampling frame has been made.
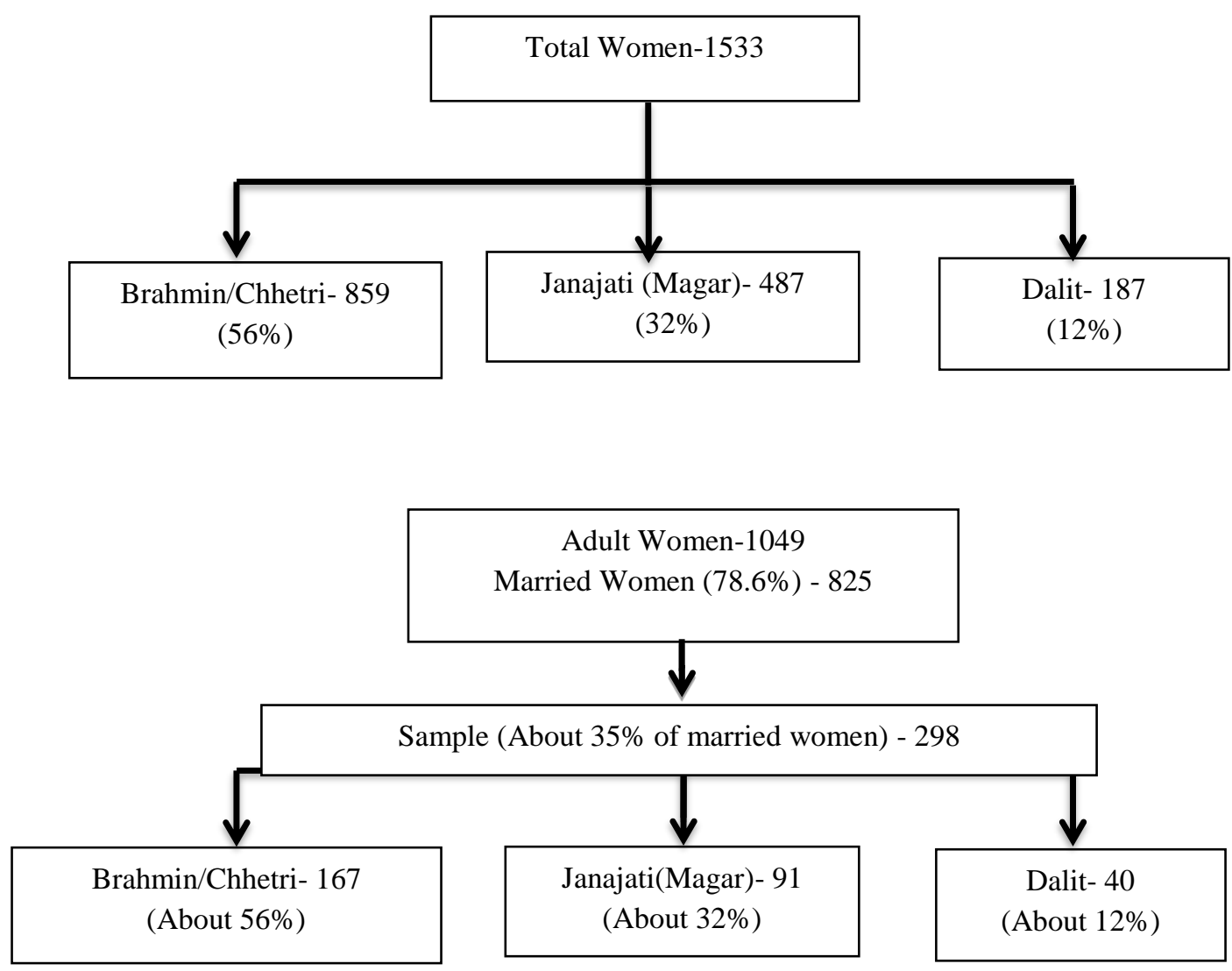

Figure 2: Sampling Frame \{Source: NDHS (2011) [10]\} 


\subsubsection{Population and Sample}

All the ever-married women of Somadi VDC are considered as population and the selected women i.e. 298 ever married women are considered as sample of the study.

\subsubsection{Research Design:}

This study is based on the cross-sectional research design. CEB is taken as dependent variable and various socioeconomic and demographic factors are taken as independent variables.

\subsection{Data Analysis Procedure}

First of all, the descriptive analysis of the variables used in study is made using various statistical tools like mean, median, mode, standard deviation, minimum, maximum, quartiles, frequency, percentage, etc. For the next approach, for fitting the binary logistic regression taking CEB as outcome variable categorizing it into two categories viz. ' 2 or less' and 'more than 2' regressing on various independent variables, significant variables are selected using univariate binary logistic regression for each possible variable. Consequently, the presence of colinearity among the selected independent variables is checked using variance inflation factors (VIFs) for each variable. Then, for the proper selection of the significant variables, forward stepwise and backward stepwise methods are adopted and then the set of variables suggested by both the methods are used for the final model.The overall significance of model coefficients is tested using Omnibus test. The goodness of fit of the logistic regression model was tested by Hosmer and Lemeshow test. The degree of explanation of the variation in response variable by the covariates in the model is described using Cox \& Snell R Square and Nagelkerke R Square. All the analysis is made using computer application IBM SPSS.

\section{Results and Discussion}

\subsection{Age of Respondent}

The descriptive information of the age in years of respondents under this study is displayed in the following Table 1.

Table 1: Descriptive information of age of respondents

\begin{tabular}{|c|c|c|c|c|c|c|c|}
\hline & N & Mean & Median & Mode & S. D & Minimum & Maximum \\
\hline Age (years) & 298 & 40.01 & 36.5 & 35 & 14.586 & 17 & 85 \\
\hline
\end{tabular}

Table 1 shows the descriptive statistics of age of the study participant in which the mean age of the respondents under study is about 40 years with standard deviation 14.58. The respondents are found of age ranging from 17 years to 85 years. The half of the women under study are of age below 36.5 years while one fourth of them are below 28 years and the maximum of them are of age 35 years.

\subsection{Age at First Birth}

The descriptive information of age of the women under study at their first birth is included in the following Table 2.

Table 2: Descriptive information of age at first birth of respondents

\begin{tabular}{|c|c|c|c|c|c|}
\hline & N & Mean & S. D & Minimum & Maximum \\
\hline Age at first birth & 298 & 19.82 & 3.297 & 12 & 30 \\
\hline
\end{tabular}

Table 2 shows the mean age at first birth of the women under study is found to be about 20 years with standard deviation 3.3 years ranging from 12 to 30 years. The one fourth of them started to give birth at the age of under 17 years, half of them did under the age of 20 years and one fourth did at 22 years and above. The maximum number of them started it at the age of 20 years. 
Factors Associated with Children Ever Born: A Case Study of Somadi Village Development Committee of Palpa District, Nepal

\subsection{Total Children Ever Born}

The descriptive information of age of the women under study at their first birth is included in the following Table 3.

Table 3: Descriptive information of total CEB to the respondents

\begin{tabular}{|c|c|c|c|c|c|}
\hline & N & Mean & S. D & Minimum & Maximum \\
\hline Total CEB & 298 & 3.19 & 1.949 & 0 & 13 \\
\hline
\end{tabular}

Table 3 shows the mean of the total CEB to the women under study, in which mean age is found to be about 3 with standard deviation 1.95 ranging from 0 to 13 . The one fourth of them have given birth to less than 2 children, half of them gave to birth less than 3 children and one fourth of them have given birth to 4 or more children. The maximum number of them has given birth to 3 children. By categorizing the women into groups having 2 or less children and having more than 2 children, the following information can be shown (Table 4)

Table 4: Percentages of women on the basis of CEB to them

\begin{tabular}{|l|c|c|}
\hline CEB & Number of women & Percent \\
\hline 2 or less & 121 & 40.6 \\
\hline More than 2 & 177 & 59.4 \\
\hline Total & 298 & 100 \\
\hline
\end{tabular}

Table 4 shows the percentage of women on the basis of CEB, it shows that about $60 \%$ of the women have more than 2 children ever born. Table 5 shows the age wise distribution of CEB, in less than 30 years of age, CEB less than or equal to two is $88 \%$, while more than 2 is $12 \%$, in 30-34 years of age, CEB less than or equal to two is $50 \%$, while more than 2 is also $50 \%$, in $30-35$ years of age, CEB less than or equal to two is $39.10 \%$, while more than 2 is $60.90 \%$, in 40 or more years of age, CEB less than or equal to two is $10.20 \%$, while more than 2 is $89.80 \%$. Figure 3 shows that about half of the women of the study area are seen without any knowledge of contraceptive and/or family planning.

Table 5: Age wise distribution of $C E B$

\begin{tabular}{|l|l|l|l|}
\hline \multirow{2}{*}{ Age(years) } & \multicolumn{2}{|c|}{ CEB } & \multirow{2}{*}{ Total } \\
\cline { 2 - 3 } & \multicolumn{1}{|c|}{ 2 or less } & \multicolumn{1}{|c|}{ More than 2 } & \\
\hline Less than 30 & $73(88 \%)$ & $10(12 \%)$ & $83(100 \%)$ \\
\hline $30-34$ & $16(50 \%)$ & $16(50 \%)$ & $32(100 \%)$ \\
\hline $35-39$ & $18(39.10 \%)$ & $28(60.90 \%)$ & $46(100 \%)$ \\
\hline 40 and above & $14(10.20 \%)$ & $132(89.80 \%)$ & $137(100 \%)$ \\
\hline
\end{tabular}

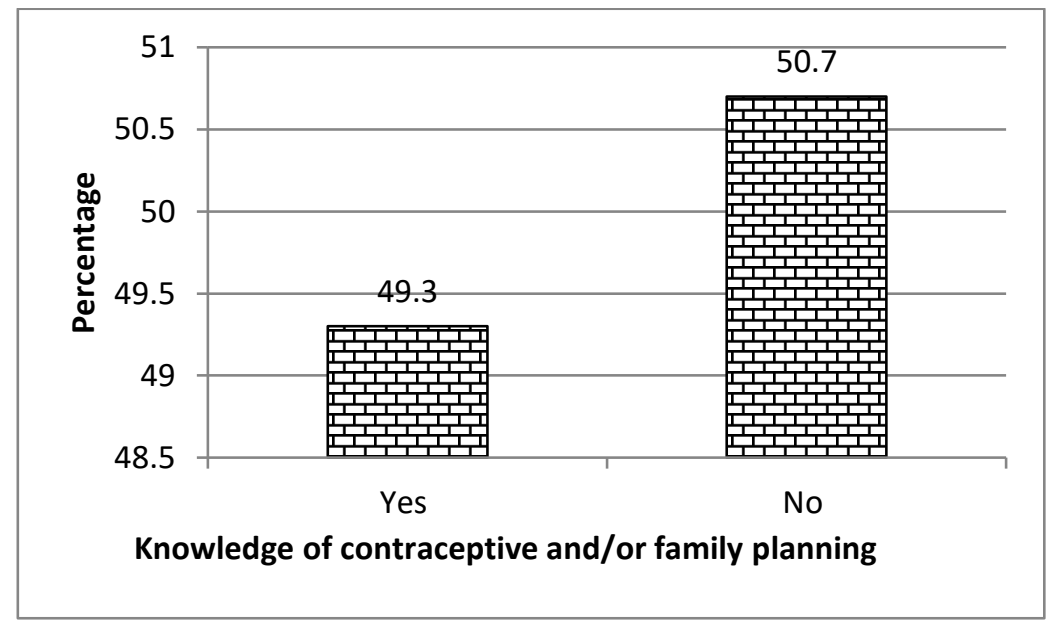

Figure 3: Percentages of women based on their knowledge about contraceptive/family planning 


\subsection{Family Structure}

The Figure 4 given below gives the number and proportion of the women on the basis of type of their family structure. This Figure 4 shows that more than $50 \%$ of the women under study have joint family

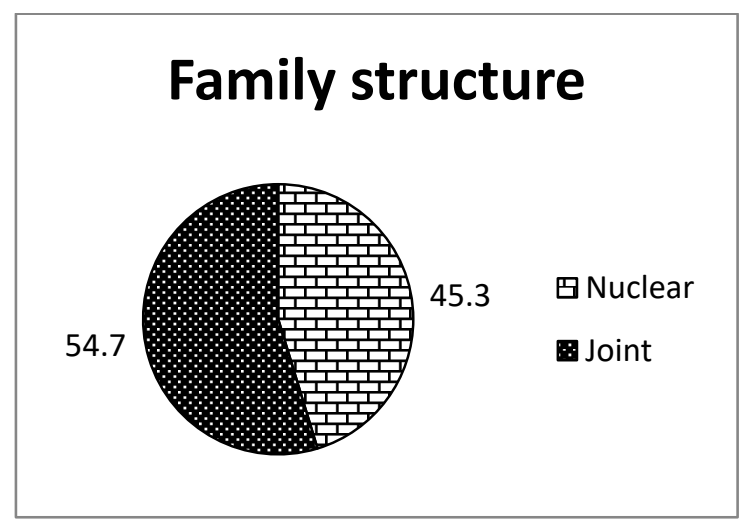

Figure 4: Percentages of women on the basis of their family structure

\subsection{Family Income}

The following Table 6 contains the information on family income of the women under study.

Table 6: Descriptive information of monthly family income of the respondents

\begin{tabular}{|l|r|r|r|r|r|}
\hline & N & Mean & S. D & \multicolumn{1}{l|}{ Minimum } & \multicolumn{1}{l|}{ Maximum } \\
\hline Family income (* Rs.1000) & 298 & 12.73 & 7.24 & 1.2 & 50 \\
\hline
\end{tabular}

Above table 6 show the descriptive statistics of income. The mean income of the women under study is found to be about Rs. 13,000 per month with standard deviation Rs. 7,240 ranging from Rs. 1,200 to Rs. 50,000. The one fourth of them have less than Rs. 7,380 income per month, half of them less than Rs. 11,000 and one fourth of them have Rs. 17,000 and above. The maximum number of them have Rs. 7,000 income per month.

\subsection{Regression Model for CEB}

By considering the total $\mathrm{CEB}$ as an outcome variable categorizing it into two categories viz. women having less of 2 children and women having more than 2 children, binary logistic regression model is fitted regressing on various socioeconomic and demographic factors. This section contains various information obtained from the fitted model. Before running the regression model, screening of the independent variables as made with the help of univariate binary logistic regression model individually for each of the possible variables. Consequently, forward stepwise and backward stepwise methods are adopted for appropriate selection of the covariates. To check whether the multicollinearity is present or not, variance inflation factors (VIFs) are used. The adequacy of the fitted model is checked using Omnibus test, Pseudo $\mathrm{R}$ square and Hosmer and Lameshow test.

\subsection{Selection of the Significant Variables}

This section includes the information about the significance of possible variables. Firstly, the variables are selected using univariate binary logistic regression for each possible factor and then forward stepwise and backward stepwise methods are adopted for appropriate selection of the covariates.

\subsection{Testing of Significance of the Different Possible Variables}

This section contains the results of the tests adopted for selecting significant variables using univariate binary logistic regression separately for each variable taking categorized CEB as outcome variable. 
Factors Associated with Children Ever Born: A Case Study of Somadi Village Development Committee of Palpa District, Nepal

\subsubsection{Age of Women}

The Table 7 contains the information obtained from the univariate logistic regression to see the significance of age on CEB.

Table 7: Test of significance of age on CEB to the women

\begin{tabular}{|l|c|c|c|c|c|c|}
\hline & Coefficient & S.E. & Wald & Df & p-value & OR \\
\hline Age & 0.12 & 0.015 & 60.401 & 1 & $<0.001$ & 1.127 \\
\hline Constant & -4.062 & 0.557 & 53.212 & 1 & $<0.001$ & 0.017 \\
\hline
\end{tabular}

Table 7 shows the test of significance of age on CEB to the women. Since, the p-value obtained is less than 0.05. It indicates that the age of women has significant impact on CEB at $5 \%$ level of significance. The odd of having more than 2 children is about 13\% higher to the women of age one year older as compared to the younger women.

\subsubsection{Age of Husband}

The following Table 8 shows the result of test of significance of age of husband on CEB to the women using univariate binary logistic regression. Table 8 shows the test of significance of age of husband on CEB to the women. It shows that the age of husband has also significant impact on CEB to the women. The odd of having more than 2 children is about $14 \%$ higher to the women having husband of age one year older as compared to those having younger husband.

Table 8: Test of significance of age of husband on CEB to the women

\begin{tabular}{|l|c|c|c|c|c|c|}
\hline & Coef. & S.E. & Wald & Df & p-value & OR \\
\hline Age of husband & 0.126 & 0.016 & 62.675 & 1 & $<0.001$ & 1.135 \\
\hline Constant & -4.916 & 0.649 & 57.338 & 1 & $<0.001$ & 0.007 \\
\hline
\end{tabular}

\subsubsection{Age at Marriage}

Table 9 represents the variation in CEB to the women on the basis of their marital age. Table 9 shows the result of test of significance of age at marriage on $\mathrm{CEB}$ to the women using univariate binary logistic regression. Table 10 shows that the age at marriage also has a significant impact on CEB to the women. The women who marry at the age below 18 years are 3.62 times more likely to have more than 2 children ever born as compared to those who get married at or after the age 18 years.

Table 9: Cross tabulation of age at marriage and CEB to the women

\begin{tabular}{|l|l|l|l|}
\hline \multirow{2}{*}{ Age at marriage } & \multicolumn{2}{|c|}{ CEB } & \multirow{2}{*}{ Total } \\
\cline { 2 - 3 } & 2 or less & More than 2 & \\
\hline Less than 18 & $41(26.30 \%)$ & $115(73.70 \%)$ & $156(100 \%)$ \\
\hline 18 or above & $40(56.30 \%)$ & $62(43.70)$ & $142(100 \%)$ \\
\hline Total & $121(40.60)$ & $117(59.40 \%)$ & $298(100 \%)$ \\
\hline
\end{tabular}

Table 10: Test of significance of age at marriage on CEB to the women

\begin{tabular}{|l|c|c|c|c|c|c|}
\hline & Coef. & S.E. & Wald & df & p-value & Odds ratio \\
\hline Less than 18 ( 18 or above) & 1.286 & 0.248 & 26.808 & 1 & 0 & 3.619 \\
\hline Constant & -0.255 & 0.169 & 2.269 & 1 & 0.132 & 0.775 \\
\hline
\end{tabular}




\subsubsection{Age at First Birth}

The following Table 11 shows the result of test of significance of age at marriage on CEB to the women using univariate binary logistic regression. The age at first birth has a significant impact on CEB to the women. If a woman starts to give birth one-year later then the odd of having more than 2 children ever born decreases by $16 \%$. Table 12 shows that the increase in education level leads to decrease fertility.

Table 11: Test of significance of age at first birth on CEB to the women

\begin{tabular}{|l|c|c|c|c|c|c|}
\hline & coefficient & S.E. & Wald & Df & p-value & odds ratio \\
\hline Age at first birth & -0.174 & 0.039 & 19.84 & 1 & $<0.001$ & 0.84 \\
\hline Constant & 3.853 & 0.793 & 23.629 & 1 & $<0.001$ & 47.143 \\
\hline
\end{tabular}

Table 12: Cross tabulation of education and CEB to the women

\begin{tabular}{|l|l|l|l|}
\hline \multirow{2}{*}{ Education } & \multicolumn{1}{c|}{ CEB } & \multirow{2}{*}{ Total } \\
\cline { 2 - 4 } & \multicolumn{1}{c|}{ 2 or less } & \multicolumn{1}{c|}{ More than 2 } & \multirow{2}{*}{$108(100 \%)$} \\
\hline No Formal Education & $17(15.70 \%)$ & $91(84.30 \%)$ & $68(100 \%)$ \\
\hline Secondary and above & $18(26.50 \%)$ & $50(73.50 \%)$ & $122(100 \%)$ \\
\hline Primary & $86(70.50 \%)$ & $36(29.50 \%)$ & $\mathbf{2 9 8}(\mathbf{1 0 0 \%})$ \\
\hline Total & $\mathbf{1 2 1}(\mathbf{4 0 . 6 0 \% )}$ & $\mathbf{1 7 7}(\mathbf{5 9 . 4 0 \% )}$ & \\
\hline
\end{tabular}

The following Table 13 shows the result of test of significance of education of women on CEB to them using univariate binary logistic regression. It shows there is significant impact of education on CEB to the women. As compared to the women having secondary and above education, the no formal education women are about 13 times likely to have more than $2 \mathrm{CEB}$, the women having primary level education are 6.64 times more likely to have more than $2 \mathrm{CEB}$.

Table 13: Test of significance of education on CEB to the women

\begin{tabular}{|l|r|r|r|r|r|r|}
\hline & \multicolumn{1}{l|}{ Coef. } & \multicolumn{1}{l|}{ S.E. } & \multicolumn{1}{l|}{ Wald } & \multicolumn{1}{l|}{ df } & p-value & OR \\
\hline Education & & & 68.863 & 2 & $<0.001$ & \\
\hline $\begin{array}{l}\text { No Formal Education } \\
\text { (secondary and above) }\end{array}$ & 2.548 & 0.33 & 59.466 & 1 & $<0.001$ & 12.788 \\
\hline Primary (secondary and above) & 1.892 & 0.339 & 31.154 & 1 & $<0.001$ & 6.636 \\
\hline Constant & -0.871 & 0.199 & 19.244 & 1 & $<0.001$ & 0.419 \\
\hline
\end{tabular}

\subsubsection{Education of Husband}

The following Table 14 represents variation in $\mathrm{CEB}$ on the basis of different education level of husband of the women. Table 14 shows the Cross tabulation of education of husband and CEB to the women. Here, the nearly the same scenario of the effect of education of husband on CEB is seen as that of the education of the women.

Table 14: Cross tabulation of education of husband and CEB to the women

\begin{tabular}{|l|l|l|l|}
\hline \multirow{2}{*}{\multicolumn{1}{c|}{ Education }} & \multicolumn{2}{c|}{ CEB } & \multirow{2}{*}{ Total } \\
\cline { 2 - 4 } & \multicolumn{1}{c|}{ 2 or less } & \multicolumn{1}{c|}{ More than 2 } & \\
\hline No Formal Education & $9(17 \%)$ & $44(83 \%)$ & $53(199 \%)$ \\
\hline Secondary and above & $23(25.60 \%)$ & $67(74.40)$ & $90(100 \%)$ \\
\hline Primary & $43(45.70 \%)$ & $51(54.30)$ & $94(100 \%)$ \\
\hline Higher & $46(75.40 \%)$ & $15(24.60 \%)$ & $61(100 \%)$ \\
\hline Total & $121(40.60 \%)$ & $177(59.40 \%)$ & $298(100 \%)$ \\
\hline
\end{tabular}


Factors Associated with Children Ever Born: A Case Study of Somadi Village Development Committee of Palpa District, Nepal

Table 15: Test of significance of education of husband on CEB to the women

\begin{tabular}{|l|c|c|c|c|c|c|}
\hline & Coef. & S.E. & Wald & df & p-value & OR \\
\hline Education & & & 45.493 & 3 & $<0.001$ & \\
\hline No Formal Education(higher) & 2.708 & 0.471 & 32.986 & 1 & $<0.001$ & 14.993 \\
\hline Primary(higher) & 2.19 & 0.383 & 32.663 & 1 & $<0.001$ & 8.933 \\
\hline Secondary(higher) & 1.291 & 0.362 & 12.701 & 1 & $<0.001$ & 3.637 \\
\hline Constant & -1.121 & 0.297 & 14.204 & 1 & $<0.001$ & 0.326 \\
\hline
\end{tabular}

Above Table 15 shows the result of test of significance of education of husband on CEB to the women using univariate binary logistic regression. Statistically, there is significant impact of education of husband on CEB to the women. As compared to the women having husband with higher level education, the women having no formal education women are about 15 times more likely to have more than 2 CEB and the women having husband with primary level and secondary level education are about 9 times and 4 times likely to have more than 2 CEB respectively.

\subsubsection{Occupation}

The following Table 16 shows that the variation in CEB on the basis of different occupation of the women. The following table shows the result of test of significance of occupation on CEB to the women using univariate binary logistic regression. It is seen that the occupation has also significant impact on CEB to the women. As compared to the housewife women, the women engaged in agricultural work are about 12 times more likely to have more than 2 CEB and the women having sales or services have $58 \%$ more odd of having more than $2 \mathrm{CEB}$.

Table16: Test of significance of occupation on CEB to the women

\begin{tabular}{|l|l|l|l|c|c|c|}
\hline & Coef. & S.E. & Wald & df & p-value & OR \\
\hline Occupation & & & 73.939 & 2 & $<0.001$ & \\
\hline Agriculture(housewife) & 2.451 & 0.29 & 71.25 & 1 & $<0.001$ & 11.603 \\
\hline Sales and services(housewife) & 0.457 & 0.559 & 0.669 & 1 & 0.413 & 1.58 \\
\hline Constant & -0.968 & 0.214 & 20.384 & 1 & $<0.001$ & 0.38 \\
\hline
\end{tabular}

\subsubsection{Occupation of Husband}

Table 17: Cross tabulation of occupation of husband and CEB to the women

\begin{tabular}{|l|l|l|c|}
\hline \multirow{2}{*}{\multicolumn{1}{c|}{ Occupation }} & \multicolumn{2}{c|}{ CEB } & \multirow{2}{*}{ Total } \\
\cline { 2 - 3 } & 2 or less & More than 2 & \\
\hline Agriculture & $37(24.70 \%)$ & $113(75.30 \%)$ & $150(100 \%)$ \\
\hline Service/Business & $84(56.80 \%)$ & $64(43.20 \%)$ & $148(100 \%)$ \\
\hline
\end{tabular}

Above Table 17 shows that the variation in CEB on the basis of different occupation of husband of the women. In agriculture occupation CEB less than or equal to 2 is $24.70 \%$ while in more than two is $75.30 \%$, like wise in service/business occupation CEB less than or equal to 2 is $56.80 \%$ while in more than two is $43.30 \%$. Table 18 shows the result of test of significance of occupation of husband on CEB to the women using univariate binary logistic regression. It shows that the occupation of husband has also significant impact on CEB. As compared to the women having husband with sales and services occupation, the odd of having more than 2 CEB is 4 times more likely. 
Upadhyay et al. Adv. J Social Sci.; Vol. 1 Issue 1, pp: 15-29, November 2017

Table 18: Test of significance of occupation of husband on CEB to the women

\begin{tabular}{|l|c|c|c|c|c|c|}
\hline & Coef. & S.E. & Wald & df & p-value & odds ratio \\
\hline Agriculture (sales and services) & 1.388 & 0.252 & 30.402 & 1 & 0 & 4.008 \\
\hline Constant & -0.272 & 0.166 & 2.686 & 1 & 0.101 & 0.762 \\
\hline
\end{tabular}

\subsubsection{Ethnicity}

The following Table 19 shows that the variation in CEB on the basis of different ethnic groups they belong to. In Brahmin/Chhetri CEB less than or equal to 2 is $43.10 \%$ while in more than two is $56.90 \%$, like wise in Magar CEB less than or equal to 2 is $40.70 \%$ while in more than two is $59.30 \%$, wise in Dalit CEB less than or equal to 2 is $30 \%$ while in more than two is $70 \%$.

Table 19: Cross tabulation of ethnicity and CEB to the women

\begin{tabular}{|l|l|l|l|}
\hline \multirow{2}{*}{ Ethnicity of Respondent } & \multicolumn{2}{|c|}{ CEB } & \multirow{2}{*}{ Total } \\
\cline { 2 - 3 } & 2 or less & More than 2 & \multirow{2}{*}{$167(100 \%)$} \\
\hline Brahmin/Chhetri & $72(43.10 \%)$ & $95(56.90 \%)$ & $91(100 \%)$ \\
\hline Magar & $37(40.70 \%)$ & $54(59.30 \%)$ & $40(100 \%)$ \\
\hline Dalit & $12(30 \%)$ & $28(70 \%)$ & $298(100 \%)$ \\
\hline Total & $121(40.60 \%)$ & $177(59.40 \%)$ & \\
\hline
\end{tabular}

Table 20: Test of significance of ethnicity on CEB to the women

\begin{tabular}{|l|c|c|c|c|c|c|}
\hline & Coef. & S.E. & Wald & Df & p-value & odds ratio \\
\hline Ethnicity & & & 2.266 & 2 & 0.322 & \\
\hline Brahmin/Chhetri(Dalit) & -0.57 & 0.379 & 2.265 & 1 & 0.132 & 0.565 \\
\hline Magar(Dalit) & -0.469 & 0.406 & 1.338 & 1 & 0.247 & 0.625 \\
\hline Constant & 0.847 & 0.345 & 6.03 & 1 & 0.014 & 2.333 \\
\hline
\end{tabular}

Above Table 20 shows the result of test of significance of ethnicity on CEB to the women using univariate binary logistic regression. It shows that there is no significant difference in CEB between the women of different ethnic groups.

\subsubsection{Knowledge of Contraceptive/Family Planning}

Table 21: Cross tabulation of knowledge of contraceptive/family planning and CEB to the women

\begin{tabular}{|l|l|l|l|}
\hline \multirow{2}{*}{ Knowledge of Contraceptive/family planning } & \multicolumn{2}{|c|}{ CEB } & \multirow{2}{*}{ Total } \\
\cline { 2 - 4 } & 2 or less & More than 2 & \\
\hline No & $26(17.20 \%)$ & $125(82.80 \%)$ & $151(100 \%)$ \\
\hline Yes & $95(64.60 \%)$ & $52(35.40 \%)$ & $147(100 \%)$ \\
\hline Total & $121(40.60 \%)$ & $177(59.40 \%)$ & $298(100)$ \\
\hline
\end{tabular}

Above Table 21 shows that the proportion of women is having higher and lower number of CEB on the basis of the knowledge about contraceptive/family planning they have. Table 22 show that the knowledge of contraceptive/family planning has significant impact on CEB to the women. As compared to the women having knowledge of contraceptive, the odd of having more than $2 \mathrm{CEB}$ is 8.78 times among those not having such knowledge.

Table 22: Test of significance of knowledge of contraceptivelfamily planning on CEB to the women

\begin{tabular}{|l|c|c|c|c|c|c|}
\hline & Coef. & S.E. & Wald & df & p-value & odds ratio \\
\hline No(Yes) & 2.173 & 0.276 & 61.944 & 1 & $<0.001$ & 8.783 \\
\hline Constant & -0.603 & 0.173 & 12.204 & 1 & $<0.001$ & 0.547 \\
\hline
\end{tabular}




\subsubsection{Family Income}

The following Table 23 represents the result of test of significance of family income on CEB to the women using univariate binary logistic regression. Table 23 that the family income per month has also significant impact on CEB to the women. If a woman has Rs. 1,000 more income in a month the odd of having more than 2 CEB decreases by $9 \%$.

Table 23: Test of significance of family income on CEB to the women

\begin{tabular}{|l|c|c|c|c|c|c|}
\hline & Coefficient & S.E. & Wald & df & p-value & odds ratio \\
\hline Income (Rs. $\left.{ }^{\circ} 000\right)$ & -0.094 & 0.02 & 23.014 & 1 & $<0.001$ & 0.91 \\
\hline Constant & 1.59 & 0.279 & 32.541 & 1 & $<0.001$ & 4.904 \\
\hline
\end{tabular}

\subsubsection{Family Structure}

The following Table 24 shows that the variation in CEB on the basis of their family structure. Table 24 shows that the variation in $\mathrm{CEB}$ on the basis of different family structure of the women. In nuclear family CEB less than or equal to 2 is $48.10 \%$ while in more than two is $51.90 \%$, like wise in joint family CEB less than or equal to 2 is $34.40 \%$ while in more than two is $65.60 \%$.

Table 24: Cross tabulation of family structure and CEB to the women

\begin{tabular}{|l|l|l|l|}
\hline \multirow{2}{*}{ Family structure } & \multicolumn{2}{c|}{ CEB } & \multirow{2}{*}{ Total } \\
\cline { 2 - 3 } & 2 or less & More than 2 & \\
\hline Nuclear & $65(48.10 \%)$ & $70(51.90 \%)$ & $135(100 \%)$ \\
\hline Joint & $56(34.40 \%)$ & $107(65.60 \%)$ & $163(100 \%)$ \\
\hline Total & $121(40.60 \%)$ & $177(59.40 \%)$ & $298(100 \%)$ \\
\hline
\end{tabular}

Table 25: Test of significance of family structure on CEB to the women

\begin{tabular}{|l|c|c|c|c|c|c|}
\hline & Coef. & S.E. & Wald & df & p-value & odds ratio \\
\hline Nuclear(Joint) & -0.573 & 0.238 & 5.78 & 1 & 0.016 & 0.564 \\
\hline Constant & 0.647 & 0.165 & 15.411 & 1 & $<0.001$ & 1.911 \\
\hline
\end{tabular}

The above Table 25 shows the structure of the family has significant impact on CEB to the women. As compared to the women from joint family, the odd of having more than 2 CEB is about $44 \%$ less among the women from nuclear family.

\subsection{Test of Multicollinearity}

Before running multiple binary logistic regression, the collinearity among the covariates to be used should be tested. To see whether there is collinearity among the covariates or not, variance inflation factors (VIFs) are calculated for each of the selected variables having significant impact on CEB to the women. In Table 26 all the values of VIFs for all variables are seen to be less than 10. It indicates that the variables have no any sign of collinearity.

Here, the variables 'education' and 'knowledge of contraceptive/family planning' may have same scenario of impact on CEB because they have significant association (Appendix A). While using both of the variables simultaneously in the model, it may lead to a fallacious result. Hence, only one of them is used in the model to be fitted. It may be convenience to use 'knowledge of contraceptive/family planning' rather than 'education'. 
Upadhyay et al. Adv. J Social Sci.; Vol. 1 Issue 1, pp: 15-29, November 2017

Table 26: Test of Multicollinearity

\begin{tabular}{|l|c|c|}
\hline \multirow{2}{*}{\multicolumn{1}{|c|}{ Variables }} & \multicolumn{2}{c|}{ Collinearity Statistics } \\
\cline { 2 - 3 } & Tolerance & VIF \\
\hline Age at marriage & 0.498 & 2.007 \\
\hline Age at first birth & 0.514 & 1.947 \\
\hline Education & 0.289 & 3.46 \\
\hline Education of husband & 0.341 & 2.931 \\
\hline Occupation & 0.554 & 1.806 \\
\hline Occupation of husband & 0.65 & 1.539 \\
\hline Knowledge of Contraceptive/family planning & 0.395 & 2.533 \\
\hline Family income ('000) & 0.629 & 1.59 \\
\hline Family structure & 0.964 & 1.037 \\
\hline
\end{tabular}

\subsection{Forward Stepwise (Likelihood Ratio)}

For the proper selection of significant covariates, forward stepwise is adopted. The result obtained is described below.

\subsection{Variables not in the Equation}

The following Table 27 shows that the variables which are seen insignificant from forward stepwise method. Table 27 shows that the variables Education of husband Age at first birth, Family income, Occupation and Family structure have no significant impact on CEB to the women under study.

Table27: Variables not in the equation

\begin{tabular}{|l|c|c|c|}
\hline Variables & Score & Df & p-value \\
\hline Education of husband & 0.02 & 1 & 0.888 \\
\hline Age at first birth & 1.181 & 1 & 0.277 \\
\hline Family income & 0.18 & 1 & 0.672 \\
\hline Occupation & 0.198 & 1 & 0.656 \\
\hline Family structure & 2.197 & 1 & 0.138 \\
\hline Overall Statistics & 3.594 & 5 & 0.609 \\
\hline
\end{tabular}

\subsection{Model if Term Removed}

The following Table 28 represents the variables which are seen to have significant impact on CEB to the women with their significance of change in -2 Log Likelihood when they are removed from the model. Table28 shows that the variables Knowledge of contraceptive/family planning, Occupation of husband and Age at marriage have significant impact on change in likelihood if these are removed from the model. Hence, forward stepwise method suggests that the covariates Knowledge of contraceptive/family planning, Occupation of husband and Age at first marriage have significant impact on CEB to the women.

Table 28: Model if term removed

\begin{tabular}{|l|c|c|c|c|}
\hline Variable & $\begin{array}{l}\text { Model } \\
\text { Log Likelihood }\end{array}$ & $\begin{array}{l}\text { Change in } \\
-2 L o g \text { Likelihood }\end{array}$ & df & p-value \\
\hline Knowledge of contraceptive & -175.893 & 33.546 & 1 & $<0.001$ \\
\hline Occupation of husband & -161.185 & 4.13 & 1 & 0.042 \\
\hline Age at marriage & -162.467 & 6.694 & 1 & $0 . .^{`} 010$ \\
\hline
\end{tabular}




\subsection{Backward Stepwise (Likelihood Ratio)}

To conform that whether the covariates selected from forward stepwise method are significant or not, another method called backward stepwise is also adopted. The results obtained from the method have shown that the variables Education of husband Age at first birth, Family income, Occupation and Family structure are insignificant and variables Knowledge of contraceptive/family planning, Occupation of husband and Age at marriage are significant for explaining the CEB to the women under study. Since, both of the methods have suggested the same set of variables which are significant for explaining CEB to the women. Hence, the variables Knowledge of contraceptive/family planning, Occupation of husband and Age at marriage are used for model fitting.

\subsection{Fitted Model}

The result of multiple binary logistic regression model fitted for explaining CEB taking CEB (categorized) as outcome variable and above selected variables as independent variables is given in Table 29 below.

Table 29: Fitted model

\begin{tabular}{|c|c|c|c|c|c|c|c|c|}
\hline \multirow{2}{*}{ Covariates } & \multirow{2}{*}{ Coef. } & \multirow{2}{*}{ S.E. } & \multirow{2}{*}{ Wald } & \multirow{2}{*}{ df } & \multirow{2}{*}{ p-value } & \multirow{2}{*}{ OR } & \multicolumn{2}{|c|}{ 95\% C.I. for OR } \\
\hline & & & & & & & Lower & Upper \\
\hline Knowledge of contraceptive & \multirow{2}{*}{1.716} & \multirow{2}{*}{0.306} & \multirow{2}{*}{31.529} & \multirow{2}{*}{1} & \multirow{2}{*}{$<0.001$} & \multirow{2}{*}{5.56} & \multirow{2}{*}{3.055} & \multirow{2}{*}{10.12} \\
\hline $\mathrm{No}($ Yes) & & & & & & & & \\
\hline Husband occupation & \multirow{2}{*}{0.608} & \multirow{2}{*}{0.296} & \multirow{2}{*}{4.206} & \multirow{2}{*}{1} & \multirow{2}{*}{0.04} & \multirow{2}{*}{1.837} & \multirow{2}{*}{1.027} & \multirow{2}{*}{3.284} \\
\hline Agriculture (sales and services) & & & & & & & & \\
\hline Age at marriage & \multirow{2}{*}{0.733} & \multirow{2}{*}{0.282} & \multirow{2}{*}{6.759} & \multirow{2}{*}{1} & \multirow{2}{*}{0.009} & \multirow{2}{*}{2.082} & \multirow{2}{*}{1.198} & \multirow{2}{*}{3.618} \\
\hline Below18(18 or above) & & & & & & & & \\
\hline Constant & -1.038 & 0.223 & 21.75 & 1 & $<0.001$ & 0.354 & & \\
\hline
\end{tabular}

The above Table 29 shows that the variable "knowledge of contraceptive/family planning is highly significant for explaining CEB to the women under study. As compared to the women having knowledge of contraceptive/family planning, those not having such knowledge are 5.56 times more likely to have more than 2 CEB. As the same study is repeated for 100 times under the similar conditions, the calculated odds ratios lie between 3.055 and 10.12 for 95 times with standard error 1.36. On the other hand, the women having their husband engaged in agriculture have about $84 \%$ more odd of having more than 2 CEB as compared to those having their husband with sales and services occupational status. If the same study is conducted for 100 times the odds ratios lie within 1.027 and 3.284 for 95 times with standard error 1.34. Next, as compared to the women who are married at the age of 18 years or above, the odd of having more than 2 children is 2.08 times more among those who are married before reaching the age of 18 years. The $95 \%$ confidence interval of the odds ratios is 1.198 to 3.618 .

\subsection{Model Adequacy Test}

To test whether the fitted model is adequate or not, following methods are adopted.

\subsubsection{Omnibus Test of Model Coefficients}

The following Table 30 contains the information about the overall significance of the model coefficients. Table 30 shows the Omnibus Test of Model Coefficients, here p-value for calculated chi-square is seen less than 0.05 . Hence, in overall, the model coefficients are significant at $5 \%$ level of significance.

Table 30: Omnibus Test of Model Coefficients

\begin{tabular}{|l|c|c|c|}
\hline & Chi-square & Df & p-value \\
\hline Model & 84.29 & 3 & $<0.001$ \\
\hline
\end{tabular}




\subsubsection{Pseudo R Square}

To see the degree of explanation by the covariates used in the fitted model on variation in CEB, pseudo $\mathrm{R}$ squares are calculated as shown in Table 31. Cox and Snell R square Nagelkerke R Square are obtained as 0.246 and 0.332 respectively. The first one indicates that the $24.6 \%$ of the variation in CEB to the women under study is explained by the covariates used in the fitted model and second one indicates the $33.2 \%$ of the variation in CEB to the women is explained by the covariates.

Table 31: Pseudo R square

\begin{tabular}{|c|c|c|}
\hline -2 Log likelihood & Cox \& Snell R Square & Nagelkerke R Square \\
\hline 318.24 & 0.246 & 0.332 \\
\hline
\end{tabular}

\subsubsection{Hosmer and Lemeshow Test}

To see the overall goodness of fit of the model, Hosmer and Lemeshow statistic is used it shows that there is no such significance difference in observed and expected number for both of the groups viz. the women having more than $2 \mathrm{CEB}$ and those having 2 or less CEB. Also, the p-value for calculated chi-square is 0.696 which is more than 0.05 . It indicates that the fitted model is good for explaining the CEB to the women under study.

\section{Conclusion}

From the results of the study, following points has been recommended to the related authorities. The lack of knowledge of contraceptive/family planning to the women of study area is seen to be leading factor for higher number of CEB. It is recommended that various awareness programs should be conducted to spread the knowledge about contraceptive use and family planning by local and/or state level related authorities. The husbands of the women under study having agricultural occupation should also be aware about to control the fertility via various programs. The earlier marriage is also seen to be another leading factor for higher number of CEB. So, the women and related bodies to them should be aware about not to marry earlier and consequences of early marriage. The distribution of various methods of contraceptive and conduction of family planning camp should be made in local level with proper spread of knowledge about contraceptive and family planning.

\section{How to Cite this Article:}

Upadhyay, H., \& Bhandari, K. (2017, October 10). Factors Associated with Children Ever Born: A Case Study of Somadi Village Development Committee of Palpa District, Nepal. Advanced Journal of Social Science, 1(1), 15-29. https://doi.org/10.21467/ajss.1.1.15-29

\section{References}

[1] UN (1983). Manual X: Indirect Techniques for Demographic Estimation (United Nations publication, Sales No. E.83.XIII.2), annex II.

[2] UN (1990). Patterns of First Marriage: Timing and Prevalence, United Nations, New York Nations.

[3] Upadhyay, H., \& Bhusal, M. (2017). Statistical Analysis on Nutritional Status and its Associated Factors of Under Five Years Children in Nepal. Advanced Journal Of Graduate Research, 2(1), 12-24.

[4] BS (2001). Population Monograph of Nepal, Central Bureau of Statistics Kathmandu, Nepal.

[5] CBS (2012). Statistical Year Book of Nepal, Central Bureau of Statistics, Kathmandu.

[6] Risal, R. \& Shrestha, A.(1989). Fertility and its proximate determinants, South Asia study on population and programmes, UNFPA, Kathmandu, Nepal.

[7] Pant, R. D. and Archarya S.(1988). Population and Development in Nepal, National Commission on Population, Kathmandu

[8] Pant, S.(1995). Age at marriage and number of children ever born (A case study of selected wards of Kathmandu Municipality), Unpublished thesis dissertation of M.A., Central department of population studies, TU, Kathmandu, Nepal

[9] Dahal, M. K.(1992). Population and Development: Nepalese Perspective, in Bal Kumar KC (ed.) Population and Development in Nepal, Kathmandu: CDPS.

[10] NDHS (2011). Nepal Demographic and Health Survey report, New Era, Kathmandu Nepal. 